\title{
Natural Convection through Air Filter Media for Cooling of Remote Radio Heads
}

\author{
Adam Martin, Lucius Akalanne \\ Wireless R\&D, Alcatel Lucent, Swindon, United Kingdom \\ Email: adam.martin@alcatel-lucent.com
}

Received 20 May 2014; revised 9 June 2014; accepted 29 June 2014

Copyright (C) 2014 by authors and Scientific Research Publishing Inc.

This work is licensed under the Creative Commons Attribution International License (CC BY). http://creativecommons.org/licenses/by/4.0/

c) (†) Open Access

\begin{abstract}
Passive cooling techniques are cost effective and reliable methods of cooling remote radio heads (RRH). This paper investigates the plausibility of a passive cooling technique involving exchanging warm air, from the internal cavity of RRHs, with fresh ambient air, to reduce the operating temperature using natural convection across air filters. The results indicate that, an internal air filter tube structure, with width of the enclosure, running vertically up the middle of an RRH, along with 4 pleat filter sides ( $2.0 \pm 0.5 \mathrm{~cm}$ separation) provides the most effective outdoor suitable setup out of those examined. This provides a reduction in temperature of $3.9^{\circ} \mathrm{K} \pm 0.4^{\circ} \mathrm{K}$ in the $P A$ and $4.0^{\circ} \mathrm{K} \pm$ $0.4^{\circ} \mathrm{K}$ in the radio, and a reduction in mass of $0.45 \pm 0.05 \mathrm{~kg}$, and is capable of withstanding water ingress and corrosive conditions including wind driven rain and salt fog.
\end{abstract}

\section{Keywords}

\section{Natural Convection, Air Filter, Porous Media}

\section{Introduction}

High temperatures in electronics is a significant issue for many reasons, one causing the lifetime of the components to be reduced, so measures must be taken to reduce the impact of waste heat energy by removing as much as possible [2]. Heat sinks and fans are the most conventional methods of cooling electronic enclosures, but, in the case of RRHs, fans cannot be used as they are active devices, and are at an elevated risk of failure from the nature of the moving parts [3]. If a fan were to fail, it would be very difficult to replace due to the location of an RRH up a mast. Heat sinks, conversely, are highly effective, passive cooling devices and are already implemented onto RRHs, but they are heavy and bulky and work best only when strongly coupled to the heat sources, so they are only suitable to be fitted to the faces of the enclosure that share a surface with the heat sources [4]. This leaves the other faces of the enclosure providing very little cooling, and other passive methods should be 
investigated to use these wasted surfaces.

In a typical remote radio head there are two main sources of waste heat energy: the power amplifier (PA) and the radio, which are generally situated in sealed enclosure with a small air gap surrounding them.

Figure 1 shows a simplistic side view of the positioning of these devices in the unit used for tests in this paper, with other components neglected.

This paper investigates the use of gas exchange between the hot internal air space and ambient atmosphere through natural convection across air filters as a method of cooling that can be mounted to the unused surfaces.

\section{Theory}

The projected service of the devices is predicted using the Arrhenius Model [1].

$$
\text { Projected Service }=\frac{1}{e^{\frac{E_{a}}{k_{B}}\left(\frac{1}{T_{R}}-\frac{1}{T_{G}}\right)}}
$$

Equation (1) represents a prediction of the fraction of time compared to the reference lifetime that an electronic device will last for. The activation energy term varies with the component failure mechanism, as the failure mechanism is unknown $0.7 \mathrm{eV}$ will be used as a central estimate [1].

\section{Experimental Apparatus}

Figures 2-7 show the RRH setups that were tested.

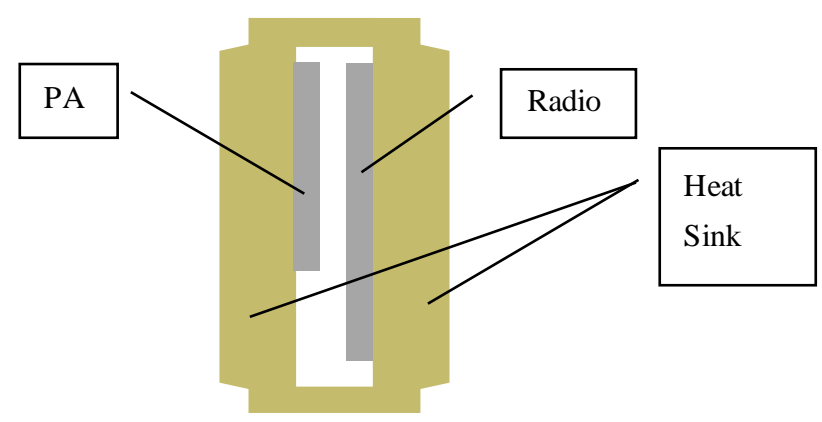

Figure 1. Typical RRH.

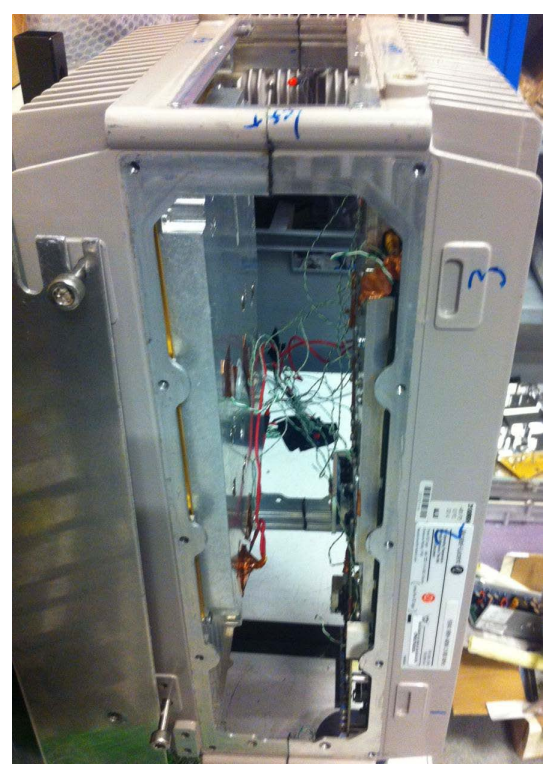

Figure 2. Open top, open sides. 


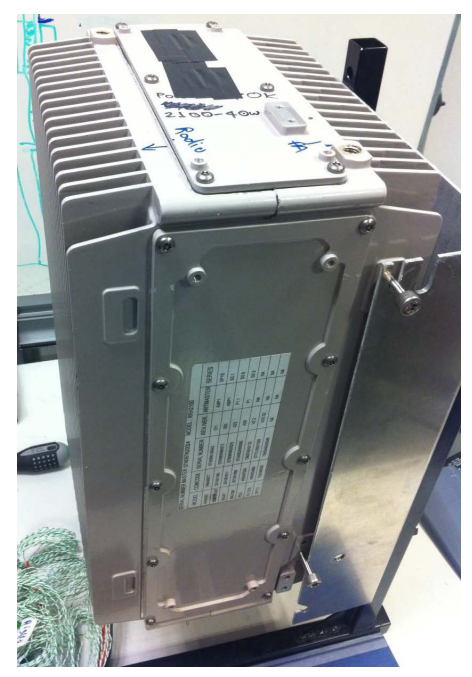

Figure 3. Standard plates.

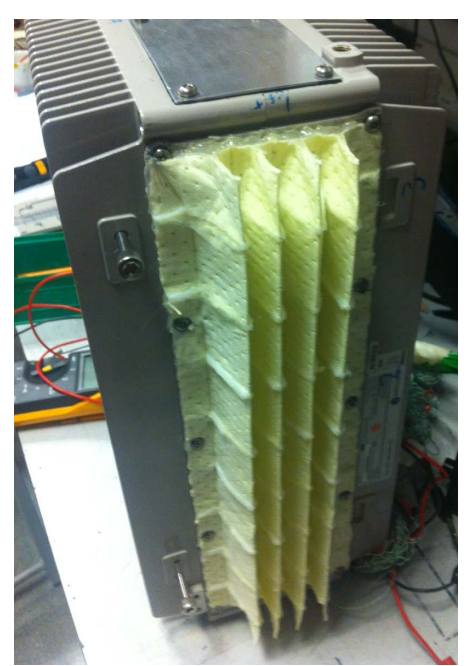

Figure 4. Side low density pleat of outdoor filter (4 Pleats).

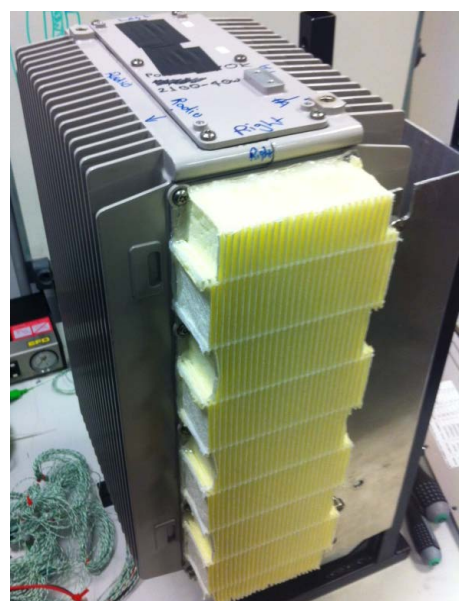

Figure 5. Side high density pleat outdoor filter (28 Pleats). 


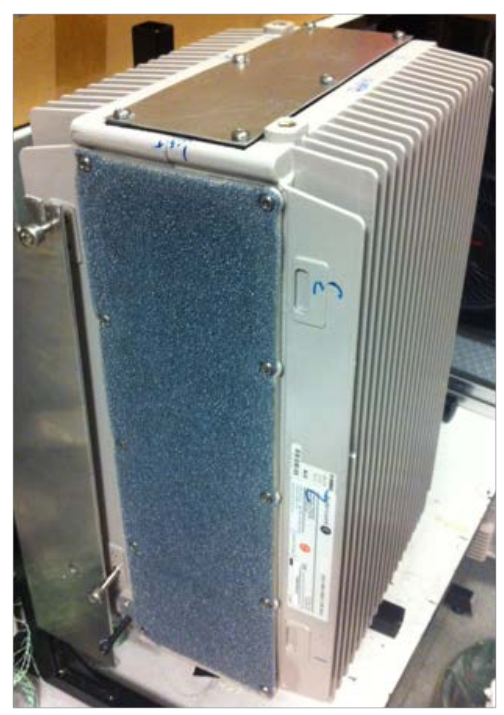

Figure 6. Indoor filter.

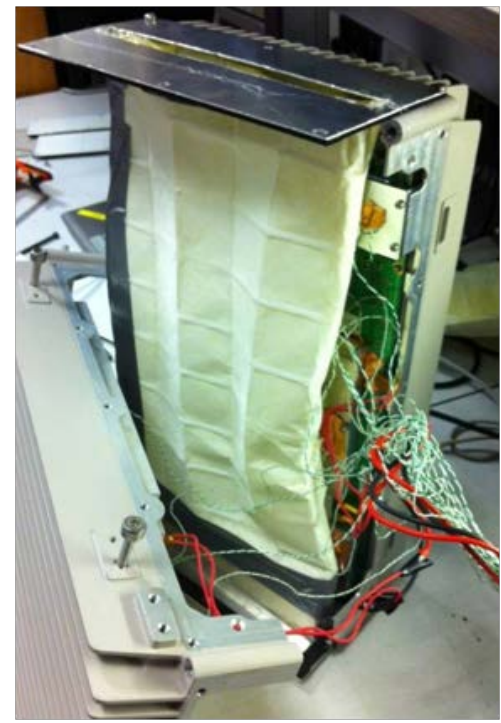

Figure 7. Vertical box tube of outdoor filter (reassembled during test).

\subsection{Control Setups}

The control setups in the figures show the fully covered RRH and the completely open setup. There were also tests taken for two types of half covered boxes not shown here; the RRH with no sides and the top and bottom are covered, and the RRH with open top and bottom and sides are covered.

\subsection{Filter Setups}

A RRH thermal mock up was built to simulate an operating RRH, using resistor circuits, with a dedicated variable power supply for both the PA and radio devices. The resistor circuits were fitted directly onto the surface of the PA and radio boards in key locations underneath the original shells, using thermal interface glue and copper tape to secure them.

Figure 8 shows the PA thermal simulator circuit, which has localised heating to the specific areas that warm during normal operation, with high power resistors that can fit below the high clamshell. Figure 9 shows the ra- 
dio circuit thermal simulator which uses lengths of transformer wire in the areas under the copper tape to simulate the more general heating of this board across larger key places, and to have a lower profile to fit beneath the low clamshell.

Nine thermocouples were mounted to the radio side of the enclosure, in the arrangement of Figure 10, to measure the air cavity temperature and 2 thermocouples were fixed under both the shell of the PA and radio to measure the temperature of the air within the clamshells.
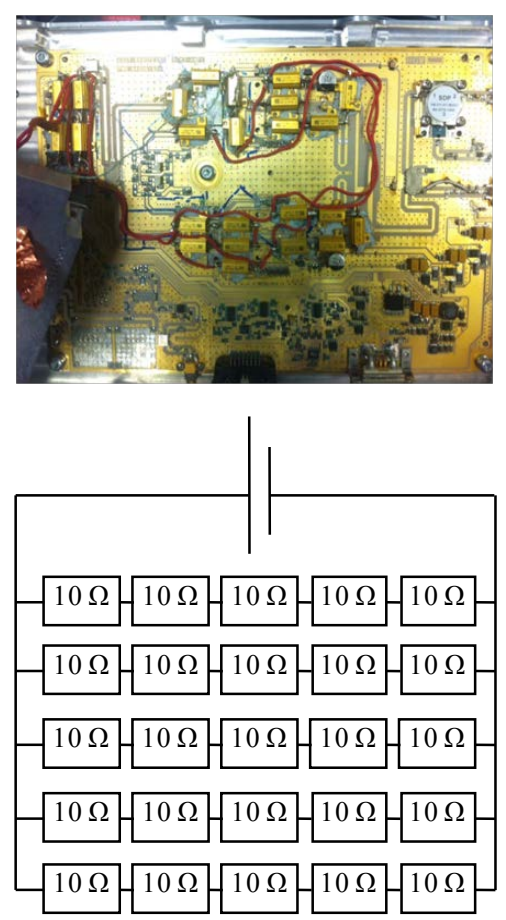

Figure 8. PA circuit heater.
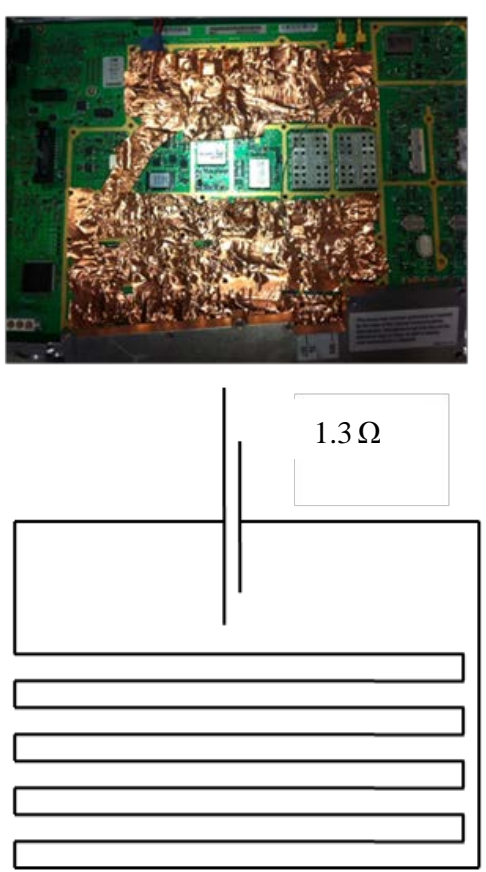

Figure 9. Radio circuit heater. 


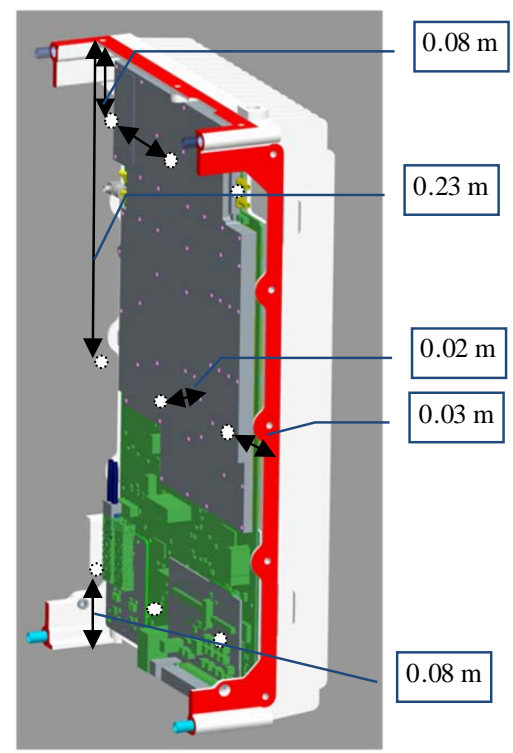

Figure 10. Internal thermocouple locations (All dimensions shown with an uncertainty of $\pm 0.01 \mathrm{~m})$.

The final rig dimensions are shown in Figure 11 and an image shown of the standard rig setup shown in Figure 3.

There are two types of air filter used in the experiments: the first is a filter designed for outdoor use and is normally fitted in conjunction with a fan for forced convection ventilation. As this filter is meant to be used with fans, the pleat structure is not optimised for natural convection flow and modifications should be made to the pleat sizes for better cooling. The benefit of this filter is that it is waterproof, salt fog resistant and has a very high particle arrestance (99\% with particle size greater than 0.3 microns across) [5]. Therefore, this filter could be used externally in harsh conditions without issues, but with this waterproofing comes the cost of a very high the pressure drop across this filter meaning a very low air flow. The second filter type is a much less robust filter, intended for internal use, which has a very low pressure resistance at the cost of no water proofing or resistance to salt fog and a significantly lower particle arrestance (see Table 1).

\section{Scientific Method}

All tests were taken with same power inputs for the PA and radio simulators within a tolerance of $\pm 1 \mathrm{~W}$ where the PA ran at $101 \pm 2 \mathrm{~W}$ and the radio at $83 \pm 1 \mathrm{~W}$. A combination of epoxy resin, hot glue and tape are used to join test setups to pass a visual inspection of a good seal.

A data logger and computer software were used to record the thermocouple readings. Once the readings had stabilised an average for each thermocouple location was taken using 500+ sets of data collected over 1 hour. The PA, radio and air cavity temperatures and uncertainties were then found by taking the average from the appropriate, individual, thermocouple temperature averages and finding the standard error in this average.

The pleat density for the side mounted outdoor filter was optimised by determining the lowest operating temperature at varying quantities of pleats. This optimised pleat density would then be tested in collaboration, and in comparison, with the other setups. Various degrees of enclosure openness are also displayed to represent a best case scenario of air flow, which was accomplished by running the setup with the plates removed.

The random error was factored in by disassembling the rig and rebuilding it, 35 times, to the same settings and re running tests to find the fluctuations.

\section{Results \& Discussion}

The data collected is displayed on graphs where the improvement, of each part, over the standard reference plate setup is shown. This gives the best visualisation for the changes in temperature. This is very simply calculated 


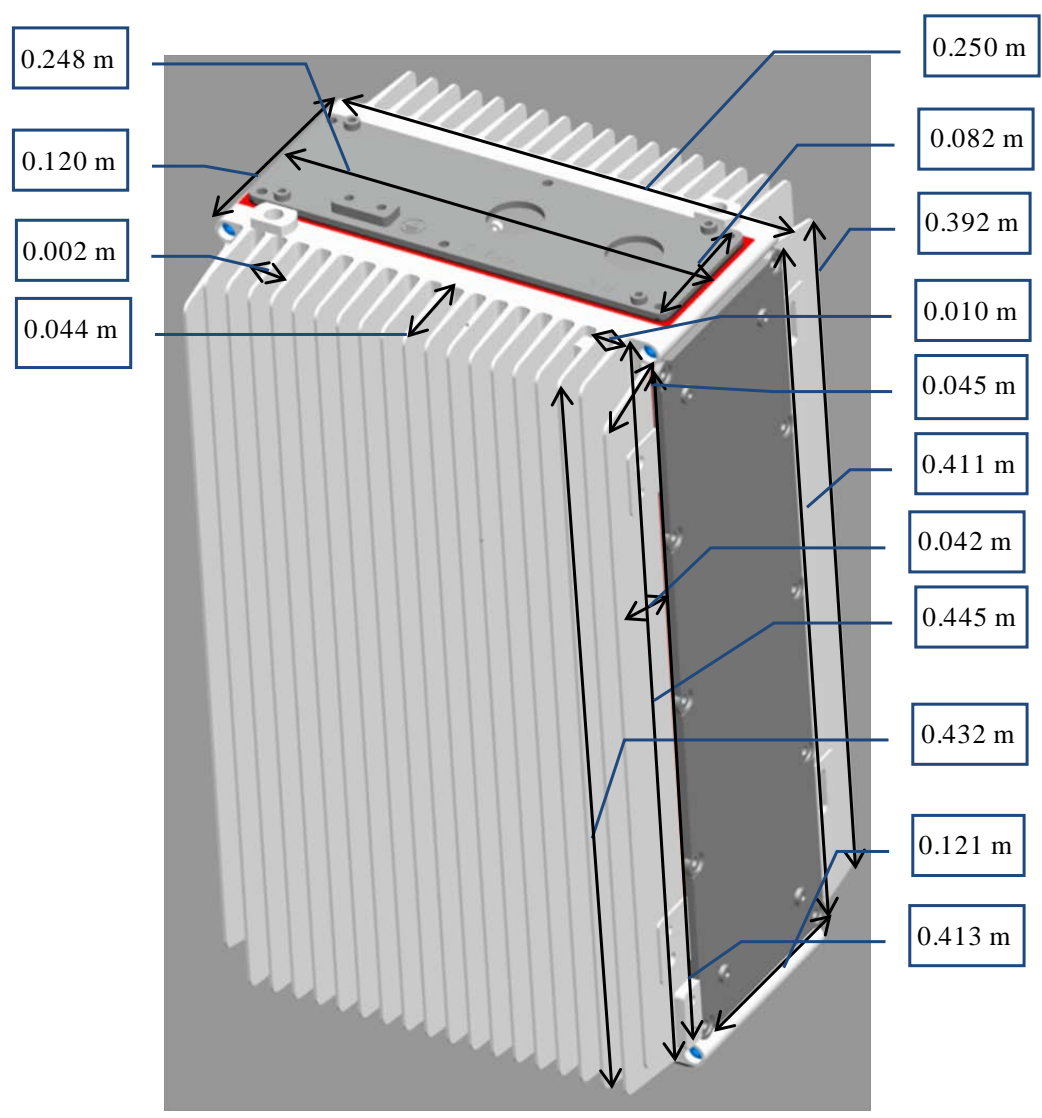

Figure 11. Full RRH Diagram. Connection holes like those seen on top are sealed during testing. All dimensions shown have an uncertainty of $\pm 0.0005 \mathrm{~m}$.

Table 1. Filter properties (tested with particle size greater than and including 0.3 microns) [5] [6].

\begin{tabular}{ccc}
\hline Filter Type & Arrestance/\% & Average Initial Pressure Resistance/Pa \\
\hline Outdoor Filter & 99 & $50-100$ \\
Indoor Filter & 65 & 9.95 \\
\hline
\end{tabular}

by taking the data, which is normalised to $25^{\circ} \mathrm{C}$, and substituting it away from the reference data, also normalised, for each thermocouple location, and then taking the average across these thermocouples to get the part average. These data points then have higher positive values for greater improvement.

Figure 12 shows the pleat width optimisation results, and out of those tested, 4 pleats in the outdoor filter is reduces the operating temperature by the greatest amount. This is what will now be used in following results for the comparisons to other methods.

Figure 13 shows the full spread of results from all methods mentioned in this paper with all associative errors. It can be seen that the outdoor tube filter performs better than the pleated sides. This is likely due to the combination of factors such as removing less metal surface area for the mounting of the filter to allow for more heat exchange through other means, reducing the space between the heat sources and the filter and reducing the overall internal air volume. The temperature can be reduced even further by combining the methods to maximise the filter surface area. Where combining the pleated sides and the central tube is more effective than each on their own and surprisingly even surpassed the cooling potential of the, much lower pressure drop, flat indoor side filter in the devices themselves, but not the internal air temperature.

Table 2 and Table 3 give the predicted lifetime extension of the electronics in the device as a result of the reduced temperature, using Equation (1), which demonstrates a life extension of up to $30 \%$ and $40 \%$ in the PA and radio respectively with the activation energy approximation of $0.7 \mathrm{eV}$. 


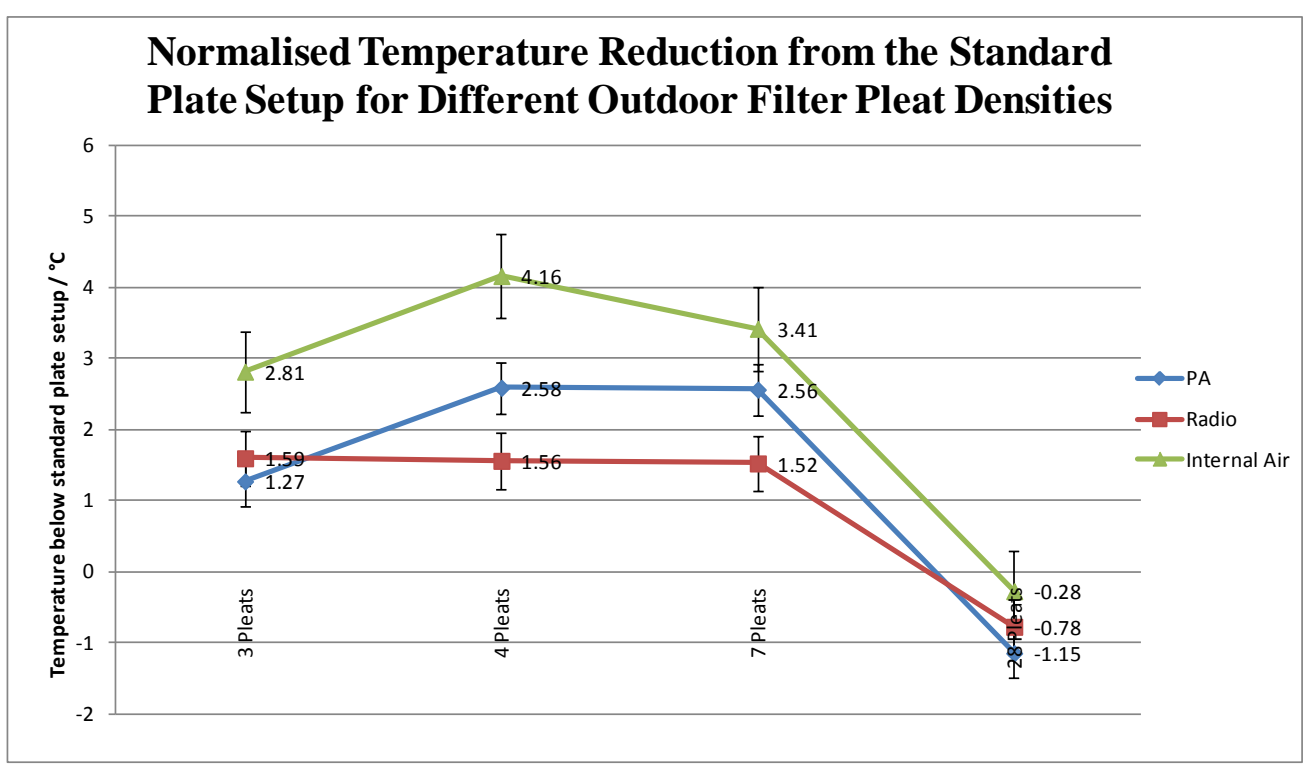

Figure 12. Pleat width optimisation.

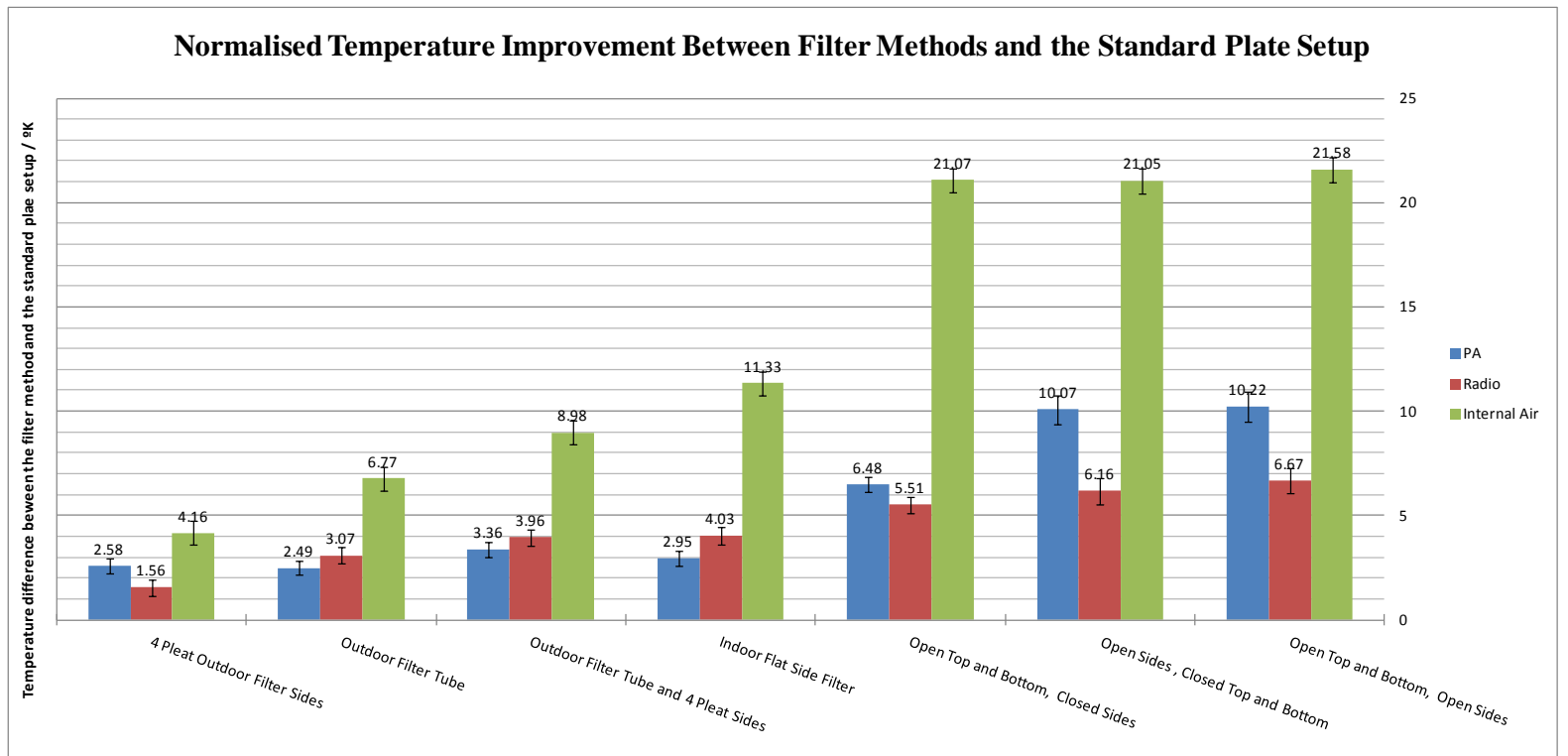

Figure 13. Full results.

Table 2. PA lifetime predictions as a result of reduced temperatures.

\begin{tabular}{ccccc}
\hline Device & PA Temperature $\left({ }^{\circ} \mathrm{K}\right)$ & Error $\left( \pm^{\circ} \mathrm{K}\right)$ & PA Lifetime & Error $( \pm)$ \\
\hline Reference (Standard Sealed Plates) & 349.0 & 0.4 & 1.0 & 0.0 \\
4 Pleat Outdoor Filter Sides & 346.4 & 0.4 & 1.2 & 0.3 \\
Outdoor Filter Tube & 346.5 & 0.4 & 1.2 & 0.3 \\
Outdoor Filter Tube and 4 Pleat Sides & 345.1 & 0.4 & 1.3 & 0.2 \\
Indoor Flat Side Filter & 346.0 & 0.4 & 1.2 & 0.3 \\
Open Top and Bottom, Closed Sides & 342.5 & 0.4 & 1.6 & 0.2 \\
Open Sides, Closed Top and Bottom & 338.9 & 0.7 & 2.0 & 0.2 \\
Open Top and Bottom, Open Sides & 338.8 & 0.7 & 2.0 & 0.2 \\
\hline
\end{tabular}


Table 3. Radio lifetime predictions as a result of reduced temperatures.

\begin{tabular}{ccccc}
\hline Device & Radio Temperature $\left({ }^{\circ} \mathrm{K}\right)$ & Error $\left( \pm{ }^{\circ} \mathrm{K}\right)$ & Radio Lifetime & Error $( \pm)$ \\
\hline Reference (Standard Sealed Plates) & 329.9 & 0.4 & 1.0 & 0.0 \\
4 Pleat Outdoor Filter Sides & 328.4 & 0.4 & 1.1 & 0.6 \\
Outdoor Filter Tube & 326.9 & 0.4 & 1.3 & 0.3 \\
Outdoor Filter Tube and 4 Pleat Sides & 325.9 & 0.4 & 1.4 & 0.3 \\
Indoor Flat Side Filter & 325.9 & 0.4 & 0.3 & 0.3 \\
Open Top and Bottom, Closed Sides & 324.4 & 0.4 & 1.6 & 0.3 \\
Open Sides, Closed Top and Bottom & 323.8 & 0.6 & 1.7 & 0.3 \\
\hline Open Top and Bottom, Open Sides & 323.3 & 0.6 & 0.3 \\
\hline
\end{tabular}

\section{Conclusions}

A multitude of natural convection based air filter cooling methods have been tested in conjunction with existing heat sinks, and it is found that an outdoor suitable air filter has provided a temperature reduction of $3.9^{\circ} \mathrm{K} \pm$ $0.4^{\circ} \mathrm{K}$ in the PA and $4.0^{\circ} \mathrm{K} \pm 0.4^{\circ} \mathrm{K}$ in the radio, in the best case, which results in a $30 \%$ and $40 \%$ increase in predicted lifetime of the assets respectively, with a further added benefit of a reduction in mass of the unit as a whole of $0.45 \pm 0.05 \mathrm{Kg}$ ( $3 \%$ improvement). These figures demonstrate that this approach to passive cooling has potential and should be pursued further to refine the construction and material for optimum cooling and weight reduction and possibly test other applications.

Although, there are some issues that may arise and will need to be addressed upon further development and consideration of use in real world scenarios such as the effect of wind on the cooling performance of the air filters. An extra issue, for the side filters, arises from the fragile nature of the filter construct, which will need substantial protection in external use to shield from debris and potential vandalism that may damage or puncture the filter and open the electronics inside to all manners of environmental damage; robust polycarbonate solar shields are already used on remote radio heads which may be substantial enough for this, but could need reinforcing. The internal tube methods have an extra advantage over the side filters here as they will need less protection due to being hidden from most direct angles.

\section{References}

[1] Ohring, M. (1998) Reliability and Failure of Electronic Materials and Devices. Academic Press, San Diego, $214-215$.

[2] McCluskey, P. and Grzybowski, R.R. (1998) Reliability Concerns in High Temperature Electronic Systems. Proceedings of High-Temperature Electronic Materials, Devices and Sensors Conference, San Diego, 22-27 February 1998, 199-200.

[3] Zapach, T.G. (2009) Thermal and Mechanical Design Considerations. www.tektelic.com/white-paper.pdf

[4] Chung, D.D.L. (2001) Thermal Interface Materials. Journal of Materials Engineering and Performance, 10, 56-59.

[5] W.L. Gore \& Associates, Inc. (2013) GORE® Cooling Filters-ABS Standard Filter Product.

[6] Universal Air Filter (2012) Quadrafoam ${ }^{\mathrm{TM}}$ Air Filters NEBS FF-5x, FF-3 Universal Air Filter. 
A. Martin, L. Akalanne

Nomenclature.

\begin{tabular}{ccc}
\hline Symbol & Meaning & Units and Value if Constant \\
\hline $\mathrm{E}_{\mathrm{a}}$ & Activation Energy & $\mathrm{J}(\mathrm{Use} 0.7 \mathrm{eV})[1]$ \\
$\mathrm{k}_{\mathrm{B}}$ & Boltzmann Constant & $1.3806488 \times 10^{-23} \mathrm{~m}^{2} \cdot \mathrm{kg} \cdot \mathrm{s}^{-2} \cdot \mathrm{K}^{-1}$ \\
$\mathrm{PA}$ & Power Amplifier & \\
$\mathrm{RRH}$ & Remote Radio Head & $\mathrm{K}$ \\
$\mathrm{T}_{\mathrm{G}}$ & Genuine Temperature & $\mathrm{K}$ \\
$\mathrm{T}_{\mathrm{R}}$ & Reference Temperature & \\
\hline
\end{tabular}


Scientific Research Publishing (SCIRP) is one of the largest Open Access journal publishers. It is currently publishing more than 200 open access, online, peer-reviewed journals covering a wide range of academic disciplines. SCIRP serves the worldwide academic communities and contributes to the progress and application of science with its publication.

Other selected journals from SCIRP are listed as below. Submit your manuscript to us via either submit@scirp.org or Online Submission Portal.
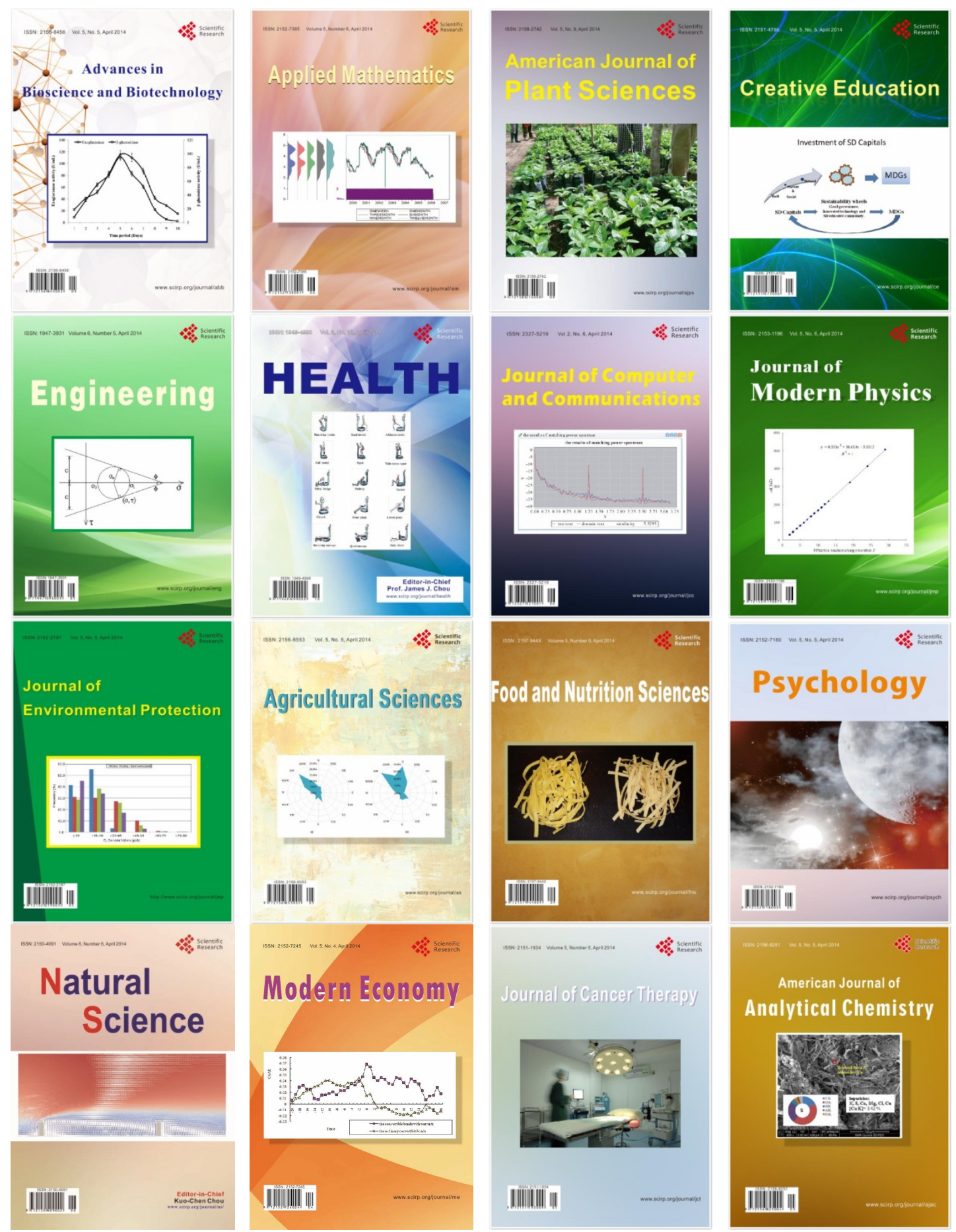